Journal of Animal and Veterinary Advances $10(4): 545-551,2011$

ISSN: $1680-5593$

(C) Medwell Journals, 2011

\title{
Spawning, Maturity Length and Size Selectivity for Pikeperch (Sander lucioperca) in Seyhan Dam Lake
}

\author{
${ }^{1}$ Caner Enver Ozyurt, ${ }^{1}$ Volkan Baris Kiyaga, ${ }^{2}$ Sinan Mavruk and ${ }^{1}$ Erhan Akamca \\ ${ }^{1}$ Department of Fishing and Fish Processing Technology, ${ }^{2}$ Department of Basic Sciences, \\ Faculty of Fisheries, Cukurova University, Adana, Turkey
}

\begin{abstract}
This study was conducted in Seyhan Dam lake between June 2007-2008. About 778 pikeperch (Sander lucioperca, Percidae) individuals were examined by means of monthly sampling and their spawning times and first sexual maturity lengths were determined. The findings obtained displayed that pikeperch in Seyhan Dam lake spawned after the month of February and the male and the female pikeperch reached the first maturity lengths of $256 \mathrm{~mm}$ TL (206 mm SL) and $264 \mathrm{~mm}$ TL (216 mm SL), respectively. Furthermore, the size selectivities of the pikeperch were estimated by using monofilament gillnets with mesh openings of $40,44,48$ and $52 \mathrm{~mm}$. For the estimation of size selectivity, the lowest deviation value was observed for the log-normal model among the selectivity curves drawn by using normal location, normal scale, log normal, gamma and bimodal distributions.
\end{abstract}

Key words: Maturity length, pikeperch, size selectivity, spawning, deviation value

\section{INTRODUCTION}

One of the most significant species of the freshwater fishery production by means of fishing in Turkey is pikeperch (Sander lucioperca, Percidae). A considerable part of the amount obtained by fishing is processed and then exported to the European countries.

On the other hand, a constant decreasing trend is observed in the annual production amount of this species. The production amount which was annually near 3000 tons at the end of $1990 \mathrm{~s}$, displayed a fluctuation between 1600 and 1900 tons during 1999-2004 with a significant decrease. Moreover, a regular decrease in the productions had occurred following 2004 (1852 tons) and the total production amount was decreased to 1346 tons in 2008. This situation shows that total production amount obtained by means of fishing, decreased $>50 \%$ compared with 1990s (Fig. 1).

Seyhan Dam lake is an important area for fishing pikeperch in which $>100$ professional fishers are active (Fig. 2). Monofilament plain gillnets are generally used for fishing. A few fishers fish by using longline or harpoon in the lake (Ozyurt and Avsar, 2003). A significant part of the pikeperch obtained by fishing in this area is sold to the processing plants and the fishes processed in the plants are generally exported to the foreign countries. The rest of the pikeperch are freshly consumed in the domestic market.

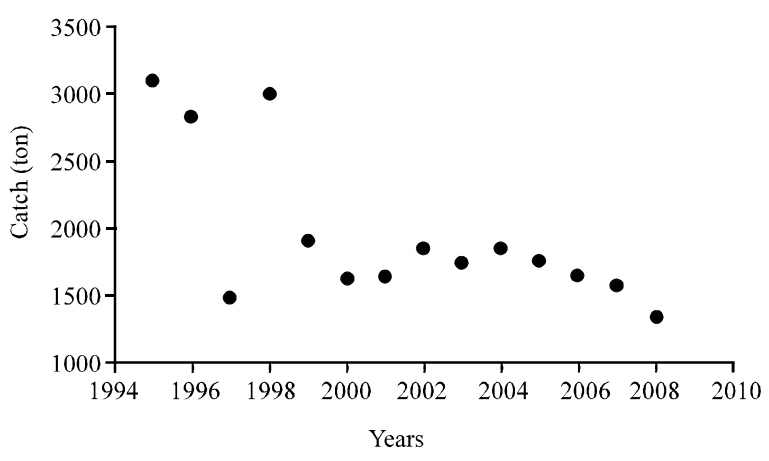

Fig. 1: The changes in the amount of pikeperch production by fishing according to the years

The fishermen state that the amount of pikeperch obtained by fishing in the Seyhan Dam lake has been decreased significantly in the recent years. It is not possible to prove the ratio of this decrease mentioned by the fishermen, since there is no data on the amount of pikeperch obtained by fishing exists. On the other hand, it was determined that the mesh sizes of gillnets used for pikeperch fishing in Seyhan Dam lake went through a significant decrease in last decade. Ozyurt and Avsar (2002) stated that monofilament gillnets with mesh sizes of 56,60 and $64 \mathrm{~mm}$ were used for pikeperch fishing in Seyhan Dam lake. Nonetheless, plain monofilament gillnets with 40-44 m mesh sizes were also used in recent periods.

Corresponding Author: Caner Enver Ozyurt, Department of Fishing and Fish Processing Technology, Faculty of Fisheries, Cukurova University, 01330 Balcali, Adana, Turkey 


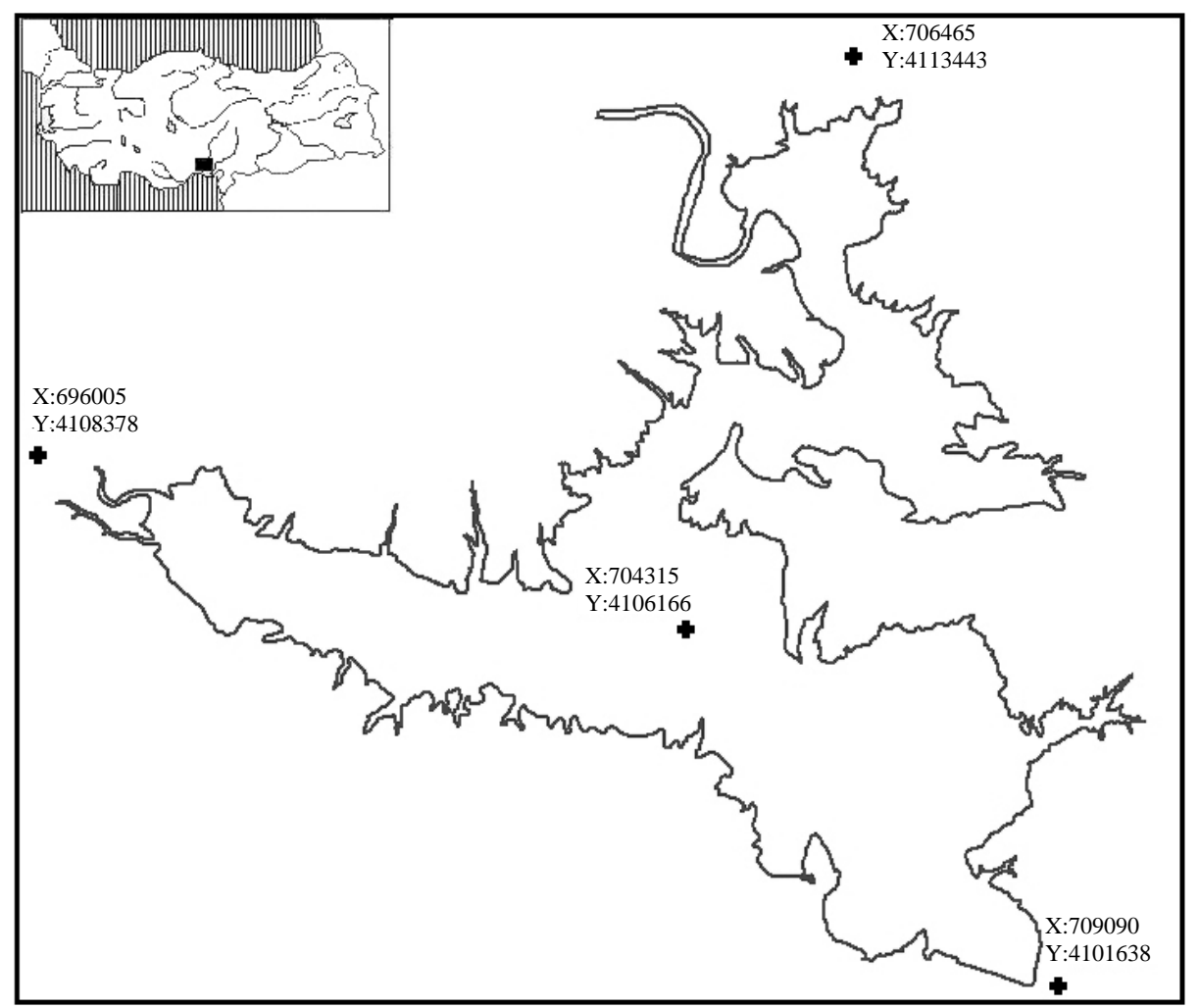

Fig. 2: Seyhan Dam lake (UTM)

This decrease in the mesh sizes displays that the average lengths of the individuals obtained by fishing were also decreased. The average lengths of the fishes obtained from fishing are related to the deaths caused by fishing (Beverton and Holt, 2004) and the decrease in the average length is one of the indicators of overfishing (Allan et al., 2005).

The legal minimum fishing length in Seyhan Dam lake is $26 \mathrm{~cm}$. Moreover, pikeperch fishing between 15 March and 30 April is completely banned. On the other hand, only one study exists regarding the first sexual maturity lengths and spawning times of pikeperch distributed in Seyhan Dam lake (Ozyurt and Avsar, 2002). No data exists regarding the size selectivity of the monofilament gillnet used in fishing.

On the other hand, the knowledge of the size selectivity of fishing gear types is crucial to the fishery management in order to maximize a sustainable yield (Millar and Holst, 1997; Huse et al., 2000) because the mesh sizes can be controlled to restrict the size of fish captured and selection curves can be used to calculate the mesh size required. A minimum value of mesh size can be used to limit the catch of immature fish or reinforce the minimum landing size regulation (Santos et al., 1998). The first maturity lengths and spawning times of the pikeperch distributed in Seyhan Dam lake and size selectivity of the monofilament gillnets used in fishing were tried to be determined in this study. A contribution to the knowledge on the biology of the pikeperch and fishery management was attempted to be made with the findings obtained from the study. Furthermore, suggestions regarding how the existing prohibitions and limits should be re-organized were presented based on the findings obtained.

\section{MATERIALS AND METHODS}

Spawning time and length at first maturity: The field works were monthly conducted in the time period between June 2007 and June 2008 in Seyhan Dam lake. Some of the monthly samples were directly obtained from the fishers in the lake. On the other hand, research purposed fishing by using monofilament plain gillnets with different mesh sizes $(40,44,48,54$ and $56 \mathrm{~mm})$ was conducted during 15 March 2008 to 30 May 2008.

Total, fork and standard lengths (in the mm variable), total and somatic weights (with the precision of $0.001 \mathrm{~g}$ ), sexualities, gonads, testicle weights (with the precision of $0.0001 \mathrm{~g}$ ) of the monthly obtained samples were determined. The seasonal timing of reproduction (spawning time) is often identified from the changes in the 
gonadosomatic index. The increases in the Gonadosomatic Index (GSI) during the reproductive cycle reflect the growth of developing oocytes during the vitellogenesis (Welcomme, 2001). The GSI value is the highest just prior to spawning and then it declines since increasingly more section of the population contains the spent females. In this study, 788 pikeperch individuals were examined in order to determine the monthly change in the GSI values. To determine the values of GSI, the Eq. 1 presented as below were used (King, 1995):

$$
\mathrm{GSI}=\frac{\mathrm{W}}{\mathrm{T}_{\mathrm{W}}} \times 100
$$

Where:

$\mathrm{W}=$ Gonad weight $(\mathrm{g})$

$\mathrm{T}_{\mathrm{w}}=$ Somatic weight $(\mathrm{g})$

The length at the first maturity may be defined as the length at which $50 \%$ of all individuals within a population are sexually mature $\left(\mathrm{Lm}_{50}\right)$ where the mature individuals are characterized by the presence of spermatophores or ova in gonads. It is generally assumed that the size at the maturation follows a normal distribution and a plot percentage mature at length $\mathrm{P}_{\mathrm{L}}$ will follow a cumulative normal distribution there (King, 1995). This can be well described by a logistic function. A total of 788 pikeperch individuals were examined in order to determine the first maturity lengths of the pikeperch. Maturity ratios of the female and male individuals were first determined with the help of the data obtained and then fitted by using the Eq. 2 (Rickey, 1995):

$$
P_{L}=\frac{1}{\left(1+e^{(a+b) L}\right)}
$$

Where:

$\mathrm{P}_{\mathrm{L}} \quad=$ Percentage of the mature fish at length $\mathrm{L}$

$\mathrm{L}=$ The fish length

$\mathrm{a}$ and $\mathrm{b}=$ The parameter values calculated from the empirical measurements

Estimating gillnet selectivity: The gillnet selectivity for Sander lucioperca was estimated by the general statistical model SELECT (Share Each Length's Catch Total) described by Millar (1992). The application of this method on gillnets was also described by Millar and Holst (1997) and Millar and Fryer (1999). The basis of this method is to estimate the selectivity parameters by applying the Log-likelihood method. The computations were performed by PASGEAR2 software (Kolding, 1999) available at http://www.cdef.no/data/pasgear. In this method, the frequency of fish of length $\left(1_{j}\right)$ in a gillnet with mesh size $\left(m_{i}\right)$ is as shown in Eq. 3:

$$
\mathrm{N}_{\mathrm{ij}}=\mathrm{p}_{\mathrm{i}} \cdot \lambda_{\mathrm{j}} \cdot \mathrm{s}_{\mathrm{i}}(\mathrm{J})
$$

Where:

$\mathrm{p}_{\mathrm{i}}=$ The relative fishing intensity that is assumed equal for all mesh size

$\lambda_{j}=$ Number of fish of length $l_{j}$ those contacted gear

$\mathrm{s}_{\mathrm{i}}(\mathrm{J})=$ The relative selectivity function of the gear with $i$ (the mesh size) to $j$ (the length class)

These relative lengths $\left(1 / \mathrm{m}_{\mathrm{i}}\right)$ are considered in accordance with the Baranov's geometric similarity for this function (Fujimori and Tokai, 2001; Kolding, 1999).

Five kinds of probability density functions are available within the PASSGEAR software (normal location, normal scale, log normal, gamma and bimodal distributions). All of the mentioned models were tested with the aim of selecting the best evaluation model. According to Park et al. (2004), the model deviance is the approximate Chai-square $\left(\chi^{2}\right)$ distribution of which the degree of freedom is taken by $n .(k-1)-m$. In this equation, $\mathrm{n}$ is the number of length class; $\mathrm{k}$ is the number of mesh size and $\mathrm{m}$ represents the estimated model parameters. The model deviance should not be much larger than the degree of freedom. On the mentioned condition, the minimum deviance indicates the best fitting (Dincer and Bahar, 2008). Thus, the best fitting was observed in the log normal model for this study. The model is presented in Eq. 4:

$$
\frac{1}{L_{j}} \exp \left[\mu_{1}+\log \left(\frac{m_{i}}{m_{1}}\right)-\frac{\sigma^{2}}{2}-\frac{\left(\log \left(L_{j}\right)-\mu_{1}-\log \left(\frac{m_{i}}{m_{1}}\right)\right)^{2}}{2 \sigma^{2}}\right]
$$

Where:

$$
\begin{aligned}
L_{j}= & \text { Mean size of fish in size class } j \\
\sigma= & \text { Standard deviation for the length of fish for mesh } \\
& \text { size } \mathrm{i} \\
\mu_{\mathrm{i}}=\quad & \begin{array}{l}
\text { Mean length of fishes caught with mesh size } \mathrm{i} \\
\end{array} \\
& \text { (Kolding, 1999) }
\end{aligned}
$$

\section{RESULTS AND DISCUSSION}

Spawning time and length at first maturity: The monthly changes in the GSI values are shown in Fig. 3. According to the Fig. 3, the GSI values of both female and male individuals increased between the months of September and January and reached the highest values in January. A constant decrease in the GSI value is observed between February and May. Nonetheless, a sharp decrease occurs, especially in the time period between February and March 
and following March however, a slower increase is observed until May. Consequently, it can be stated that pikeperch do reproduce densely between February and March in Seyhan Dam lake.

The sexual maturity phases corresponding to the length groups for the female and male individuals can be shown in Fig. 4. The obtained findings displayed that female pikeperch reached their first maturity at the length of $264 \mathrm{~mm}$ TL (216 mm SL) whereas the first maturity lengths of the male ones were observed to be $256 \mathrm{~mm} \mathrm{TL}$ (206 mm SL).

Estimating gillnet selectivity: A total of 204 pikeperch individuals were obtained in the experimental study conducted. About 121 (59.3\%), 61 (29.9\%), 12 (5.9\%) and $10(4.9 \%)$ of these individuals were caught, respectively by using gillnets with $40,44,48$ and $52 \mathrm{~mm}$ mesh sizes. The length groups of the pikeperch caught by using gillnets $40,44,48$ and $52 \mathrm{~mm}$ mesh sizes varied between $170-225,200-230,215-235$ and $230-250 \mathrm{~mm}$, respectively. The parameters, model variances and degrees of freedom of the selectivity curves belonging to the normal scale, normal location, log-normal, gamma and bimodal models are shown in Table 1 . The lowest variance value among these models was observed for the log-normal model. The common mesh selection parameter $\mu$, relating the model length to the mesh size was found to be 5.298. On the basis of this parameter, the corresponding model

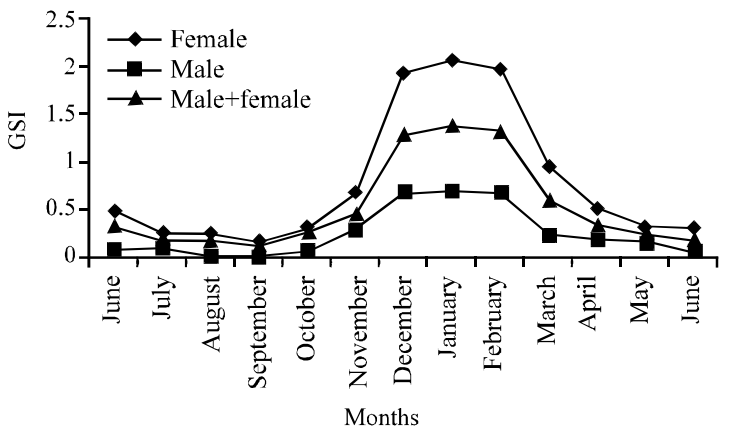

Fig. 3: Monthly changes in the GSI values lengths for $40,44,48$ and $52 \mathrm{~mm}$ meshes were calculated to be $211.92,233.11,254.30$ and $275.49 \mathrm{~mm}$, respectively. The selectivity curves for the different mesh sizes based on the log-normal model are shown in Fig. 5.

The pikeperch do spawn once a year and leave all of their eggs at once. The growth of gonad occurs in the low temperature periods when the growth of body is slower (Hokanson, 1977). The spawning temperatures can vary between $4^{\circ} \mathrm{C}$ (Raikova-Petrova and Zivkov, 1998) and $14^{\circ} \mathrm{C}$ (Hokanson, 1977). The spawning season however, can be from the end of February to the beginning of June in relation with the regions and the structure of the water source (Lehtonen et al., 1996; Raikova-Petrova and Zivkov, 1998; Becer and Ikiz, 1999).

The male individuals compared with the female ones generally reach their maturity a year earlier and at a shorter length (Lehtonen et al., 1996). Reaching maturity can occur in a wide spectrum such as 1-10 years ( Raikova-Petrova and Zivkov, 1998). The growth displays significant fluctuations in relation with the regions but generally, the southern populations do show a faster growth than the ones in the North (Lehtonen and Toivonen, 1981; Lehtonen et al., 1996).

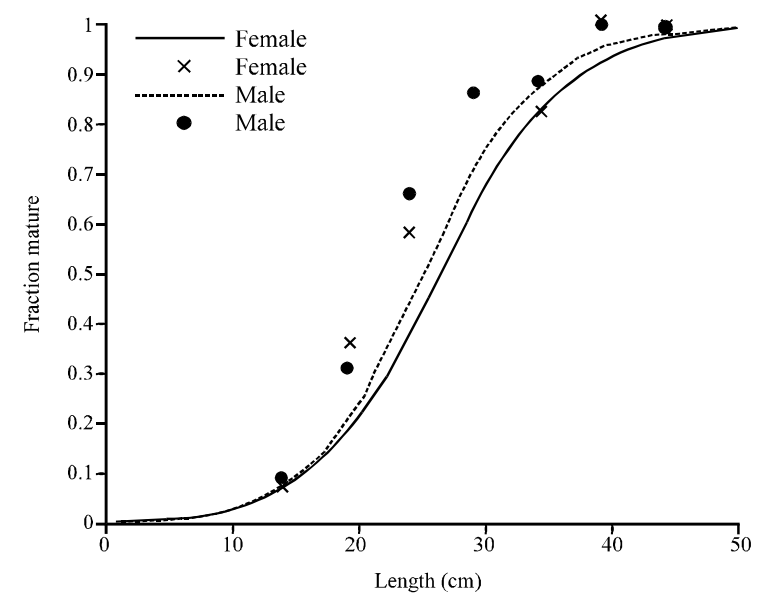

Fig. 4: Sexual maturity level according to the length groups

Table 1: Fitting result of different models of gillnet selectivity with the SELECT method for pikeperch

\begin{tabular}{|c|c|c|c|c|c|c|c|c|}
\hline \multirow{2}{*}{$\frac{\text { Model }}{\text { Normal scale }}$} & \multicolumn{5}{|c|}{ 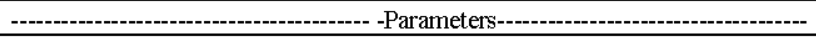 } & \multirow{2}{*}{$\begin{array}{l}\text { Deviance } \\
20.688\end{array}$} & \multirow{2}{*}{$\frac{\mathrm{df}}{27}$} & \multirow{2}{*}{$\frac{\mathrm{p} \text { value }}{0.800667}$} \\
\hline & $\mathrm{k} 1$ & $\mathrm{k} 2$ & - & - & - & & & \\
\hline & $(10.006)$ & $(0.477)$ & - & - & - & & & \\
\hline \multirow[t]{2}{*}{ Normal location } & $\mathrm{k}$ & $\sigma$ & - & - & - & 23.145 & 27 & 0.677185 \\
\hline & $(9.941)$ & $(10.531)$ & - & - & - & & & \\
\hline \multirow[t]{2}{*}{ Log normal } & $\mu_{1}$ & $\sigma$ & - & - & - & 19.554 & 27 & 848328 \\
\hline & $(5.298)$ & $(0.048)$ & - & - & - & & & \\
\hline \multirow[t]{2}{*}{ Gamma } & $\mathrm{k}$ & $\alpha$ & - & - & - & 19.871 & 27 & 0.836141 \\
\hline & $(0.023)$ & $(430.675)$ & - & - & - & & & \\
\hline \multirow[t]{2}{*}{ Bi-modal } & $\mathrm{k} 1$ & $\mathrm{k} 2$ & $\mathrm{k} 3$ & $\mathrm{k} 4$ & $w$ & 19.883 & 24 & 0.703385 \\
\hline & $(9.578)$ & $(0.281)$ & 10.241 & 0.477 & 1.191 & & & \\
\hline
\end{tabular}




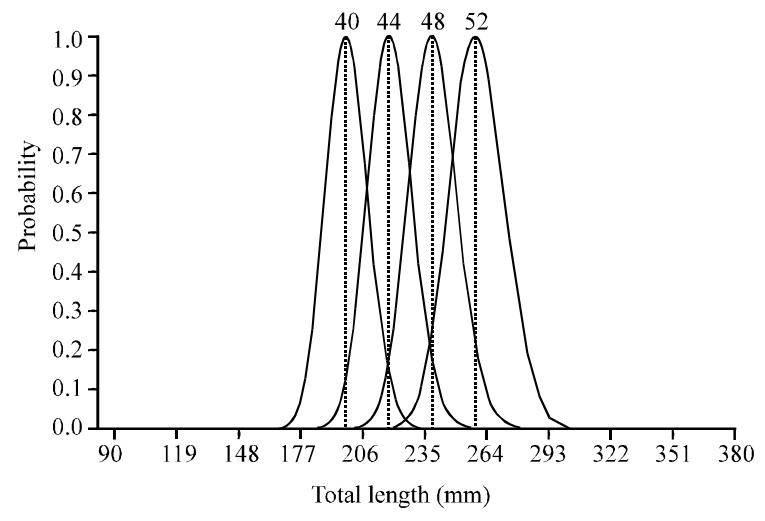

Fig. 5: Fitted gillnet selectivity curves for pikeperch

These differences in the growth, accordingly in maturity are in all probability caused by the environmental factors such as temperature and abundance of food (Lappalainen and Malinen, 2002).

Seyhan Dam lake is located on the southern boundaries of the area in which the pikeperch are distributed and in the hot temperate zone. Therefore, it can be expected that pikeperch located in this area would lay eggs at an earlier season and their individuals would reach maturity earlier when compared with the other populations. It was determined that pikeperch would spawn at $10.4^{\circ} \mathrm{C}$ water temperature during the month of February. Raikova-Petrova and Zivkov (1998) stated that pikeperch do lay eggs in Ovcharista Dam lake (South Bulgaria) which is a hot water reservoir between the temperatures of $6-12^{\circ} \mathrm{C}$ and during the end of February or March. These findings do seem compatible with the data obtained from the Seyhan Dam lake located in the south of Turkey. Moreover, Ozyurt and Avsar (2002) stated that pikeperch spawned during the month of February in the same location. In the literature that can be obtained, the minimum maturity length values were 200 and $230 \mathrm{~mm}$ SL for the males and females, respectively (Kukuradze, 1974). These values were similar with the first maturity length values ( $206 \mathrm{~mm}$ SL for males, $216 \mathrm{~mm}$ SL for females) of the pikeperch located in the Seyhan Dam lake. As a matter of fact, the first maturity length determined for the females is smaller than the first maturity length determined by Kukuradze (1974). This can probably be attributed to the fact that Seyhan Dam lake is located on the southern boundaries of the area in which the pikeperch are distributed and in the hot temperate zone.

Leavastu and Favorite (1978) stated that the stock level of the species which form school during the spawning period would decrease if they are fished in great amounts. One of the applications to prevent this decrease is to totally prohibit fishing during the spawning time
(Beverton and Holt, 2004). Male and female pikeperch individuals would migrate to the shores with light vegetations to lay eggs in the lakes (Lucas et al., 2001) and leave their eggs on stones, plant roots and other free subsubrates (Lehtonen et al., 1996). There is no record regarding how the spawning migration of the pikeperch occurs in Seyhan Dam lake.

On the other hand, the fact that spawning occurs during the month of February do indicate that female and male individuals get closer to the coastal region beginning from the month of February. Nonetheless, pikeperch fishing in Seyhan Dam lake is prohibited between 15 March and 30 April. Therefore, some of the individuals, approach to the coastal regions for spawning may have been caught before laying eggs. In other words, individuals that would constitute the future stock are decreased since mature individuals are fished before they have the chance to lay eggs.

The idea that there may be recruitment fishing in this area is reinforced when the decrease in the mesh sizes of gillnets used in the recent decade period is considered.

The best fit for pikeperch was enabled by using the log-normal model. In general, gillnet selectivity curves may approach normal curves when most fish are wedged or gilled (Hamley, 1975). On the other hand, catch data are skewed to the right, fitting better to gamma or log-normal models or multimodal models when many fish are entangled (Hamley, 1975; Pet et al., 1995; Kurkilahti et al., 1998; Dos Santos et al., 2003). Limited number of gillnet selectivity studies for pikeperch were encountered in the conducted literature review (Van Densen, 1987; Balik, 1999; Carol and Garcia-Berthou, 2007). Van Densen (1987) and Balik (1999) determined the parameters for selectivity using the method proposed by Holt (1963) whereas Carol and Garcia-Berthou (2007) used the SELECT method. Carol and Garcia-Berthou (2007) as it is in this study, determined the best fit model for the selectivity curve as the log-normal model. The general selectivity factor (5.721) estimated in the abovementioned study and the general selectivity factor (5.298) determined in this study is close in value.

The first maturity length values obtained in this study are 256 and $264 \mathrm{~mm}$ TL for male and female individuals, respectively. Nonetheless, all of the length groups obtained with $40,44,48$ and $52 \mathrm{~mm}$ gillnets utilized in this study are smaller than the first maturity length value (Fig. 6).

On the other hand, optimum fishing length should be a little bit more than the first maturity length value. Therefore, it can be stated that the optimum lengths of the monofilament gillnet used for pikeperch fishing in Seyhan Dam lake should be $270 \mathrm{~mm}$ (a little bit longer than the first 


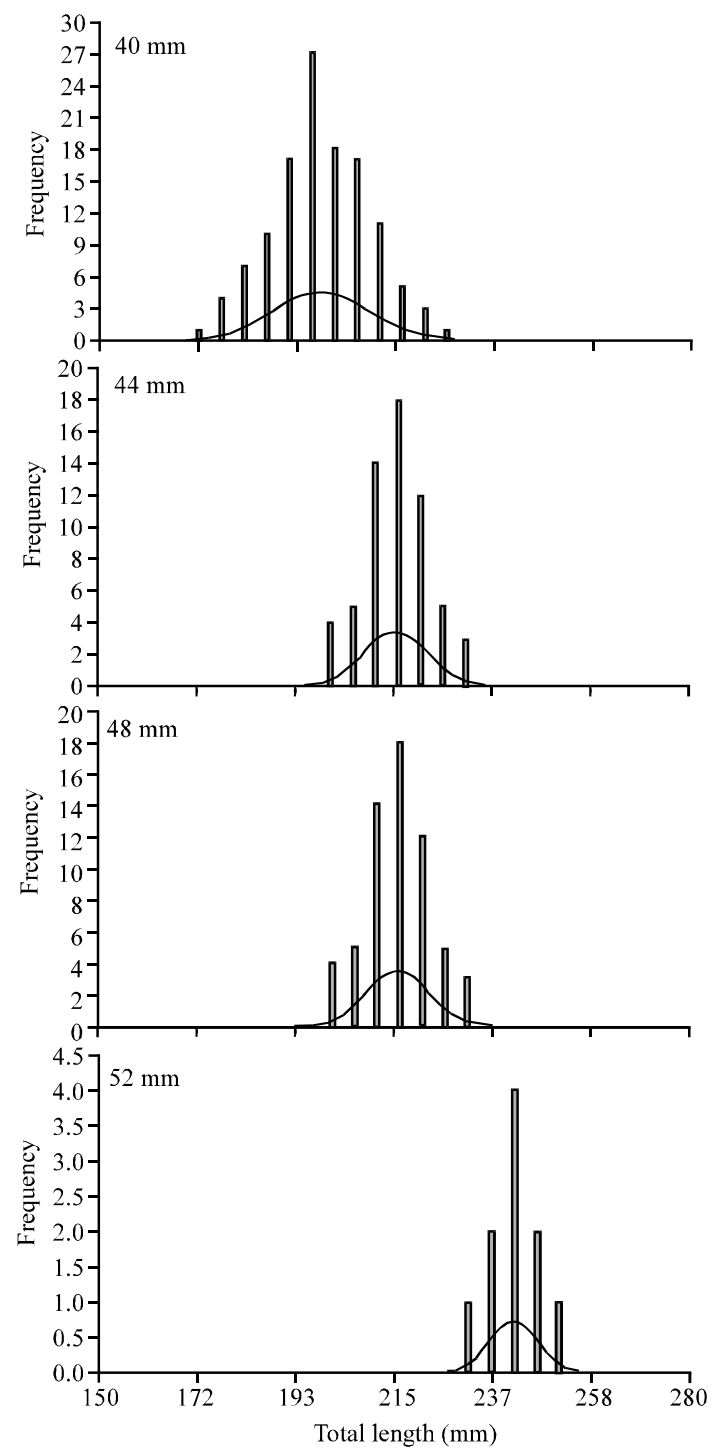

Fig. 6: Length frequency graphics and first maturity length

maturity lengths of females). It can also be said, accordingly that minimum legal fishing length of $260 \mathrm{~mm}$ applied in the Seyhan Dam lake should be increased some more.

The obtained general selectivity factor $(\mu=5.298)$ displays that optimum fishing length that is a little bit longer than the maturity length $(270 \mathrm{~mm})$ can only be enabled by using gillnets with a mesh size of $51 \mathrm{~mm}$. Considering that pikeperch fishing is implemented by professional fishers only by using gillnets with 40 and $44 \mathrm{~mm}$ mesh sizes in Seyhan Dam lake, it could be comprehended that all of the caught individuals would be the ones that did not spawn or individuals that have a fast growth. This condition on the other hand, presents the idea that there occurs a growth overfishing in the area.

\section{CONCLUSION}

It was determined both in this study and Ozyurt and Avsar (2002)'s study that pikeperch lay eggs during the February month in Seyhan Dam lake. This condition displays that the prohibition period should be applied at an earlier date than the currently applied time period between 15 March and 30 April. Therefore, fishing of mature female and male individuals approaching towards the coastal region would be prevented. Moreover, the mesh sizes of gillnets used in pikeperch fishing $(40,44 \mathrm{~mm}$ mesh sizes) should be increased to prevent fishing of sexually immature and fast growing length groups. The minimum mesh size to be used should be $51 \mathrm{~mm}$ according to the general selectivity parameter (5.298). Increasing the mesh sizes would primarily prevent fast growing and sexually immature individuals. Consequently, the overcoming of growth overfishing would be enabled at a certain level. Heikinheimo et al. (2006) stated that increasing the minimum mesh size of the nets from 43-45-50 $\mathrm{mm}$ in Archipelago Sea would cause a 50\% decrease in the fishery production amount but the value of production would be $20 \%$ more compared to the recent value after several years. Increasing the mesh sizes of nets for the Seyhan Dam lake would cause the occurrence of a similar trend in the fishery production values. Nonetheless, this decrease in the production for the first year does not seem to be acceptable for the fishers. Therefore, the method of gradually increasing in the minimum mesh sizes of nets, instead of increasing it straight to $51 \mathrm{~mm}$ at once could be implemented. Nevertheless, further studies are required on which intervals and for how long the mesh sizes should be increased to $51 \mathrm{~mm}$ to organize a more definite planning.

\section{REFERENCES}

Allan, J.D., R. Abell, Z. Hogan, C. Revenga, B.W. Taylor, R.L. Welcomme and K. Winemiller, 2005. Overfishing of Inland Waters. Bioscience, 55: 1041-1051.

Balik, I., 1999. Investigation of the selectivity of multifilament and monofilament gill nets on pikeperch (Stizostedion lucioperca (L., 1758)) fishing in Lake Beysehir. Turk. J. Zool., 23: 179-183.

Becer, Z.A. and R. Ikiz, 1999. Reproductive characteristics of pikeperch (Stizostedion lucioperca (L., 1758) in Egirdir Lake. Turk. J. Zool., 23: 919-926.

Beverton, R.J.H. and S.J. Holt, 2004. On the Dynamics of Exploited Fish Populations. The Blackburn Press, New Jersey, pp: 533.

Carol, J. and E. Garcia-Berthou, 2007. Gillnet selectivity and its relationship with body shape for eight freshwater fish species. J. Applied Ichthyology, 23: $654-660$. 
Dincer, A.C. and M. Bahar, 2008. Multiflament gillnet selectivity for the red mullet (Mullus barbatus) in the Eastern Black Sea cost of Turkey, Trabzon. Turk. J. Fish. Aquatic Sci., 8: 355-359.

Dos-Santos, M.N., M. Gaspar, C.C. Monteiro and K. Erzini, 2003. Gill net selectivity for European hake Merluccius merluccius from Southern Portugal: Implications for fishery management. Fish. Sci., 69: 873-882.

Fujimori, Y. and T. Tokai, 2001. Estimation of gillnet selectivity curve by maximum likelihood method. Fish. Sci., 67: 644-654.

Hamley, J.M., 1975. Review of gillnet selectivity. J. Fish. Res. Board Can., 32: 1943-1969.

Heikinheimo, O., J. Setala, K. Saarni and J. Raitaniemi, 2006. Impacts of mesh-size regulation of gillnets on the pikeperch fisheries in the Archipelago Sea, Finland. Fish. Res., 77: 192-199.

Hokanson, K.E.F., 1977. Temperature requirements of some percids and adaptations to the seasonal temperature cycle. J. Fish. Res. Board Can., 34: 1524-1550.

Holt, S.J., 1963. A method for determining gear selectivity and its application. ICNAF Spec. Publ. Int. Comm. Northwest Atl., 5: 106-115.

Huse, I., S. Lokkeborg and A.V. Soldal, 2000. Relative selectivity in trawl, longline and gillnet fisheries for cod and haddock. Ices J. Mar. Sci., 57: 1271-1282.

King, M.G., 1995. Fisheries Biology Assessment and Management. 1st Edn., Blackwell Science, Oxford, England, pp: 341.

Kolding, J., 1999. PASGEAR-A Data Base Package for Experimental or Artisanal Fishery Data from Passive Gears. An Introductory Manual. Dept. of Fisheries and Marine Biology, University of Bergen, Bergen, Norway, pp: 61.

Kukuradze, A.M., 1974. Characteristics of the reproductive shoal and reproduction of pike perch in the delta of and water bodies by the Danube. Voprosy Ichthyology, 14: 445-454.

Kurkilahti, M., M. Appelberg, E. Bergsrand and O. Enderlein, 1998. An indirect estimate of bimodal gillnet selectivity of smelt. J. Fish Biol., 52: 243-254.

Lappalainen, J. and T. Malinen, 2002. Effect of Area and Location on Pikeperch Yields in Finnish Lakes. In: Management and Ecology of Lake and River Fisheries, Cowx, I., (Ed.). Blackwell Science, Oxford, pp: 34-45.

Leavastu, T. and F. Favorite, 1978. Numerical evaluation of marine ecosystem. Part I. Deterministic bulk biomass model (BBM). Northwest and Alaska Fisheries Center Technical Memoranda, Seattler Wash., Processed Report, pp: 22.
Lehtonen, H. and J. Toivonen, 1981. Fresh-Water Fish. In: The Baltic Sea, Voipio, A., (Ed.). Elsevier Scientific Publications Company, Amsterdam, pp: 333-341.

Lehtonen, H., S. Hansson and H. Winkler, 1996. Biology and exploitation of pikeperch, Stizostedion lucioperca (L.), in Baltic Sea area. Ann. Zool. Fenn., 33: $525-535$.

Lucas, C.M., E. Baras, T.J. Thom, A. Ducan and O. Slavik, 2001. Migration of Freshwater Fish. Blackwell Science, Oxford, England, pp: 420.

Millar, R.B. and R. Holst, 1997. Estimation of gillnet and hook selectivity using log-linear models. ICES J. Mar. Sci., 54: 471-477.

Millar, R.B. and R.J. Fryer, 1999. Estimating the sizeselection curves of towed gears, traps, nets and hooks. Rev. Fish Biol. Fish., 9: 89-116.

Millar, R.B., 1992. Estimating the size selectivity of fishing gear by conditioning on the total catch. J. Am. Stat. Assoc., 87: 962-968.

Ozyurt, C.E. and D. Avsar, 2002. Identification of some biological characteristics for pikeperch (Sander lucioperca Bogustkaya and Naseka, 1996) in Seyhan Dam Lake (Adana). EU J. Fish. Aquatic Sci., 19: 77-84.

Ozyurt, C.E. and D. Avsar, 2003. An assessment on the new improvement to the of Seyhan Dam Lake fisheries. EU J. Fish. Aquatic Sci., 20: 199-204.

Park, C.D., E.C. Jeong, J.K. Shin, H.C. An and Y. Fujimori, 2004. Mesh selectivity of encircling gill net for gizzard shad Konosirus punctatus in the coastal sea of Korea. Fish. Sci., 70: 553-560.

Pet, J.S., C. Pet-Soede and W.L.T. van Densen, 1995. Comparison of methods for the estimation of gillnet selectivity to tilapia, cyprinids and other fish species in a Sri Lanka reservoir. Fish. Res., 24: 141-164.

Raikova-Petrova, G. and M. Zivkov, 1998. Maturity, spawning and sex ratio of pike perch, Stizostedion lucioperca (L.), in two Bulgarian reservoirs as compared to other European habitats. J. Applied Ichthyology, 14: 31-35.

Rickey, M.H., 1995. Maturity spawning and movement of arrowtooth flounder, Athereshes stomias, off Washington. Fish. Bull., 93: 127-138.

Santos, M.N., C.C. Monterio, K. Erzini and G. Lasserre, 1998. Maturation and gill-net selectivity of two small sea breams (genus Diplodus) from Algarve coast (south Portugal). Fish. Res., 36: 185-194.

Van Densen, W.L.T., 1987. Gillnet selectivity to pikeperch, Stizostedion lucioperca (L.) and perch, Perca fluviatilis L., caught mainly wedged. Aquacult. Res., 18: 95-106.

Welcomme, R., 2001. Inland Fisheries: Ecology and Management. 1st Edn., Wiley-Blackwell, Oxford, England, pp: 384. 